\title{
THE TRAVELLING OF FORKLIFTS IN WAREHOUSES
}

\author{
Burinskiene, A. \\ Faculty of Business Management, Vilnius Gediminas Technical University \\ Sauletekio ave 11, LT-10223, Vilnius, Lithuania \\ E-Mail: aurelija.burinskiene@vgtu.lt
}

\begin{abstract}
Around $75 \%$ of warehouses retrieve products manually. In these warehouses forklifts are the most expensive machines. The study pays special attention to the travelling of these machines. In order to determine potential travel distance savings, a simulation model is created. The experiments demonstrate that the travel distance of forklifts can be reduced by 27-37 \% when RF-based process is implemented comparing with travel distance when paper is used in the process. Research provided herein also defines how to optimize travelling by implementing multiple-tasks approach in WMS. The presented results show that the travel distance of forklifts can be also reduced by $9 \%$ when multiple-tasks approach is used. In addition, it is identified, how stock accuracy affects the travel distance of forklifts. The correlation between the travel distance of forklifts and stock accuracy is presented herein. (Received in February 2011, accepted in August 2011. This paper was with the author 2 months for 1 revision.)
\end{abstract}

Key Words: RF, Forklifts, Travel Distance, Accuracy, Multiple-Tasks

\section{INTRODUCTION}

Nowadays, the main issue for warehouses is how to increase their productivity. Seeking to address this issue, the research studies warehouse processes, which govern the productivity of warehouse. In order to determine possible improvements in warehouses, the travelling of forklifts is examined.

Modern Material Handling magazine has made survey with regard to warehouse systems. Representatives from different trade sub-sectors (such as electronics, automotive, medical, paper, industrial products, and others) have responded information about the automation of warehouses. The research has find out that $75 \%$ of warehouses retrieve products manually. In such warehouses forklifts are the most expensive machines due to equipment, labour and maintenance costs [1].

This shows the importance of researches in such area. In addition, the analysis of scientific literature published by leading world publishers (such as Oxford University Press, Cambridge University Press, Harvard University Press, Springer, M. E. Sharpe, Routledge, etc.) shows that only $1 \%$ of the authors, which focus on logistics issues, have taken into account forklifts and each twelfth of authors have taken into account both forklifts and productivity. In the literature authors mention that minimisation of duplicative and/or multiple handlings of pallet, as well as non-productive movements and construction of routes for the most-costly forklifts can help to increase productivity. The most of authors mention that the implementation of RF-based process and the usage of multiple-task approach are used as advanced practice seeking to increase productivity. On the other hand, scientific knowledge of circumstances and scientifically-proved solutions should be used to determine the effect of such implementations. In such complex situations it is necessary to resort to simulation models [2]. One simulation model (which is created by the author) is presented in this research. 
The object of research concerns the travelling of forklifts in warehouses. The subject of research concerns the evaluation of travel distance savings in warehouses.

The article is also based on comparative and empirical analysis.

The aim of this paper is after examining the peculiarities of forklifts travelling in warehouses, identify opportunities to reduce travel distance of forklifts.

In this paper the travelling of forklift is examined through simulation; and different experiments with this simulation model are undertaken.

\section{FORKLIFTS IN WAREHOUSE: A LITERATURE REVIEW}

Extreme pressure is placed on all functions of traditional warehouse. The warehouses have to be flexible and have possibility to increase or decrease its operations in order to meet any demand. This has both advantages and challenges. A key advantage is that warehouses are ready to underlay economic trends and seasonality [3]. A key challenge is that they have to stay competitive in today's market. This means that managers and engineers must continue to improve the performance of their warehouse operations [4].

In general, there are a lot of activities in traditional warehouses. Product typically arrives packed on a large scale and leaves packed on a smaller scale [5]. In other words, the most of products arrive in pallets, but leave packed in cases; some very fast-moving products are received in pallets and are shipped in pallets [6]. In almost all supply chains, raw materials, parts, and product inventories still need to be stored or buffered [7]. In warehouses products are received in pallets, placed to storage or pick locations, picked and sent to customers. So, the material flow is based on following activities: receiving, put-away, keeping in buffer, refilling (replenishment), picking and shipping (Fig. 1).

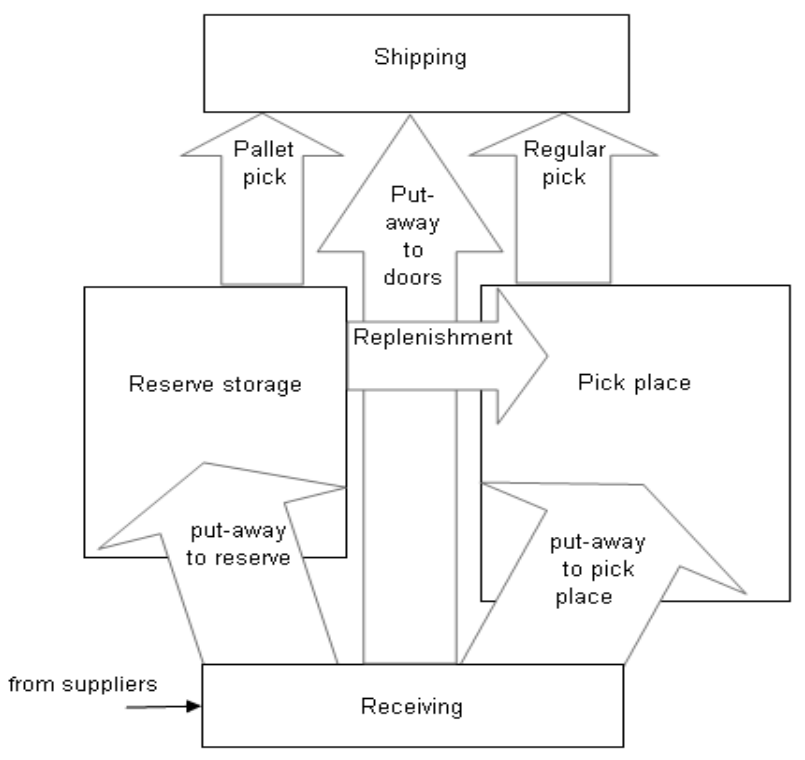

Figure 1: Main warehouse activities [7].

The receiving activity includes the unloading of products from the transport carrier, updating the inventory record, finding quantity or quality inconsistency [8]. Put-away involves the transfer of incoming pallets to storage locations. Also put-away includes physical movements between different functional areas [9]. Pallet pick is considered as retrieval of pallet from storage location to shipping doors. In literature operations with information technology-based tools are also classified into pallet picking with scanners [10]. A barcode scanner is a wireless scanning technology that communicates with the host system [11]. By 
scanning location and pallet, the driver of forklift identifies where from the pallet is taken and where is placed. During all these operations forklifts are used in traditional warehouses [12].

Replenishment is the retrieval of pallet from storage location and the placement of the same pallet to pick location. Pick location is replenished when the inventory in this location reaches some defined minimum level. Replenishment task for each pick location is generated by warehouse management system (WMS). When the minimum inventory level is reached the system triggers the replenishment task. Pallet handling during replenishment is accomplished by forklifts. There are also situations when replenishment task is combined with the task, which is called "return to storage location". Return to storage location occurs when the heights of pick and storage locations are different: for example, the height of pick location for slow moving items, which are placed in wide-aisle warehouse, is lower than the height of storage location.

Put-away to doors is performed when received pallets are transferred directly to shipping doors (these operations are also called as cross-dock operations: short stay of pallet may be required but little and no order picking is needed) [7].

Forklifts with WMS supported RF terminals are operating in warehouses, which have shelf and racks. Forklift has fork, which helps to stack material (e.g. pallet) 4-5 meters in height [13]. In addition, RF system offers high-speed communication and electronic identification [11].

Forklift is used for moving pallets. First, the driver of forklift has to be equipped with radio control device, such as RF terminal, and with the monitor, which is located on the forklift. Operations performed by forklift with RF terminal require a discrete signal that will ensure only that the desired pallet or location is identified. RF terminal is used to send messages (SME's) for the driver. The monitor on the forklift typically provides the driver instructions associated with a given operation. In addition, driver can be instructed to do stock count. During process, the driver knows where to go, what to take, and where to place. The driver of forklift does according instructions: scans a barcode or enters a location code and place pallet. When the task is finished the driver gives confirmation to host system (WMS) over local area wireless (Wi-Fi) network [14]. WMS direct forklift to perform next task in nearby area [15]. This means that if put-away and replenishment operations are handled on the same trip then there is also significant improvement in forklift productivity. But if warehouse does put-away during the day and pallet pick at night, productivity gains are limited - the combination of put-away and stock count tasks is possible during the day only [16].

Also, warehouse layout has big impact on productivity: if warehouse has receiving docks on one side and shipping docks on the other side is not as conducive to productivity gains. For the combination of put-away and pallet pick tasks, it is better if doors, which are on the same side of warehouse, are used for receiving and shipping [16].

The common objective for implementing RF-based processes is to increase productivity. Author suggests that there is a continuum of applications that range from specific application to different applications. In addition, the configuration of WMS may play a critical role in attaining different applications [17].

In order to define effect of each application in warehouse and analyse possibilities to minimise the travel distance of forklift, a simulation model is created.

\section{SIMULATION MODELS AND EXPERIMENTS}

Simulation models can be useful for analysing problems and comparing different scenarios. There are different types of simulation models. Well-known are travel-time and traveldistance models. Many factors can be incorporated in travel-time models, such as travel 
speeds, the number of forklifts working in warehouse. Some travel-time models estimate the time required to complete tasks, considering lead time, travel time, and non-efficient time [2]. Another type of models is travel-distance models. These models are used for the calculation of travel distance. Usually, travel-distance models are used for analysing the travelling of order pickers. The model presented below can also be classified as travel-distance model. In addition, this model is also used for analysing the travelling of forklifts.

\subsection{The Excel simulation model}

Based on the fact that Excel is the widely used as a statistical tool to understand concepts and to use hand-worked calculations for analyzing problems, the simulation model is built in Excel. Excel has such functionalities:

- Visual Basic macro commands;

- Set of formulas and markings;

- Excel allows building simulation models with non-standard warehouse layout solutions (for example, depot placed in the corner, etc.).

The Excel simulation model is splitted into several parts. The structure of the Excel-based simulation model is based on:

Warehouse plan. A schematic picture of the wide-aisle warehouse is shown in Fig. 2. The width of aisles is 5 metres. The items (each item with one pick location) are stored on racks and are picked in pallets from storage locations.

The considered warehouse, called a reference warehouse, has eight parallel aisles, and each aisle contains one hundred pick locations (the width of each location is 0.8 and the length is 1.2 metres). The cross-aisles make two possibilities of switching between aisles: at the front, at the rear of warehouse. The width of cross-aisles is 4.8 metres and it is used in the reference warehouse to handle the traffic. In the reference warehouse the width between racks is 3.4 metres. This is called as one corridor and is used for driving with forklift, for loading and unloading pallets from storage locations.

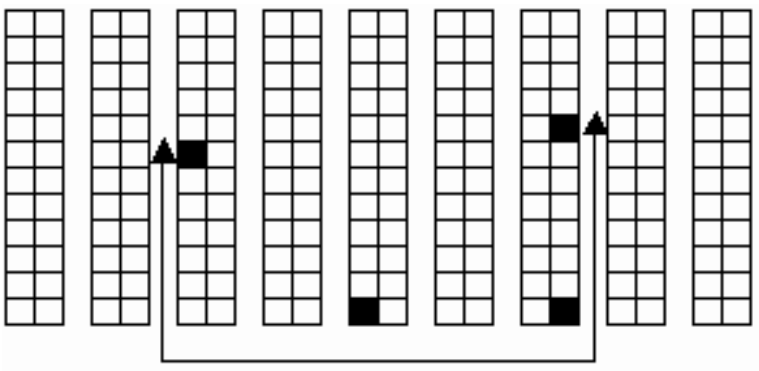

Traditional

Figure 2: The plan of warehouse.

Tasks database. Tasks are entered into a database, which contains the names of locations, date and command specifics.

Simulation on warehouse plan. Simulation uses the tasks database, where locations, which have to be replenished, are defined; for changing shift the driver of forklift moves to the depot. It is also considered that the driver of forklift drives in warehouse at the same speed. Simulation involves movements of the forklift inside the aisles, cross-aisles, as well as return to depot, which are modelled by macro commands in Visual Basic. The movements of forklift are shown in the schematic picture (representing warehouse plan). During simulation of these movements a colour is used. When the forklift moves into a new cell in the schematic picture, 
the colour in the previous cell is removed and the new cell is coloured. When forklift moves across, the differences in rows and columns of previous and current location (cells) for total distance calculation are taken into account (Fig. 3).

The movements such as put-away, pallet-pick, movements inside cross-aisles and returns to the depot are modelled by Visual Basic macro commands. Three macro command blocks are used for the algorithm:

- The first two command blocks are used for moving between even or odd locations. The forklift is moving according to the schematic picture of the reference warehouse (which is wide-aisle warehouse). Generally, during simulation the forklift is moving at the right side of the corridor and is stepping to the left side by a task request only.

- The third command block is used for returning to the depot.

If forklift moves between different aisles for any purposes (to pick pallets or to return to depot) the algorithm checks which cross-aisle is closer to the previous and next locations, and indicates the closest cross-aisle for the next movement. The algorithm each time finds the shortest way individually: the forklift has to be moved back to the cross-aisle (which is previously used to come to the aisle) or has to transfer aisle through the entire length to the next cross-aisle.

The macro command is also used for the calculation of total travel distance. It is considered, that inside the corridor, forklift is moving 0.6 metres away from the racks. When the pallet is retrieved or put, 0.6 metres till location and 0.6 metres back are added to the total travel distance. If forklift is moving from one side of corridor to another, the distance of 2.8 metres for changing sides is added. The calculation of total travel distance and the movements of forklift are activated by pressing the Visual Basic macro command button (see Fig. 3).

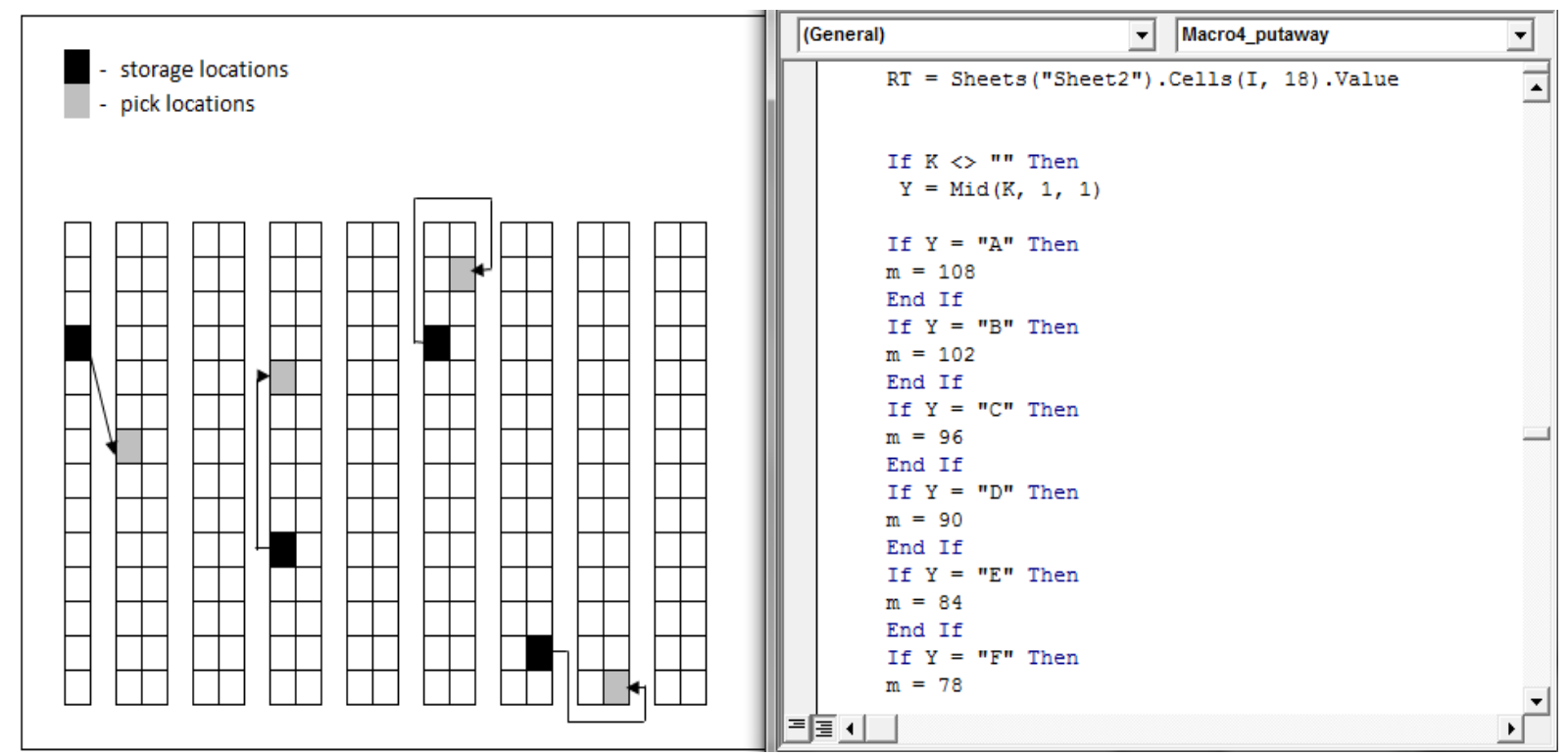

Figure 3: The Excel simulation model: warehouse plan (on the left side) and command algorithm (on the right side).

\section{Validation tests:}

- The simulated model meets real processes which occur in an ordinary warehouse. Tasks lists are entered into database based on the date, tasks and locations identification numbers.

- In ordinary warehouse around $54 \%$ of pick and storage locations are in the same aisle. The tasks, which are entered to the tasks database, are adequate to the situation in reference warehouse. 
- During simulation one forklift is performing all tasks, but in reality, many forklifts are working in warehouse, so this means that in the model a summary of travel distances of all forklifts is calculated.

- Practically the driver of forklift can return to the depot through different cross-aisles or corridors. In that case, the total travel distance can be the same or longer, as the macro command algorithm is choosing the shortest way.

\subsection{Tasks}

All tasks are entered and the sequence among them is defined in tasks database. A task is defined as an SME's and placed on specified date. SME's is transferred to the RF terminal of forklift.

In most of warehouses the replenishment of pick location can be organised based on two approaches:

- Urgent replenishment of product, which is "out of stock" in pick location;

- Replenishment of product, which has less than one day stock in pick location.

In reference warehouse one third of all replenishment tasks are performed for the products, which are "out of stock".

All replenishment tasks are entered into the database. Each of them contains the following details: date and product place (location name). Tasks can be organized in several ways. The basic variants include replenishment, put-away, pallet pick. For example, first, forklifts work with put-away tasks, after they are directed to handle pallet pick tasks.

More variants also exist, such as the combination of put-away and replenishment tasks or the combination of put-away and pallets pick tasks, etc.

In the most of cases authors, which are interested in the minimisation of forklift travel costs, analyse travel distance. Two types of travel distances are used in literature: average travel distance per task and total travel distance (for the set of tasks). The case study focuses on the last one. The authors think that by minimising an average travel distance, the total travel distance is also minimised [7].

How the tasks for single forklift are selected? Usually, it is selected based on "travel distance", which occurs if the new task is added or another storage location is selected by WMS. Each task can be directed straight to the terminal of RF forklift.

If forklift works according paper-based task list, at first forklift moves to computer station (where all tasks lists are placed), then moves to certain storage location to take pallet according to the task list, at the end, delivers pallet to a pick location and then moves to the computer station to confirm the completed task [18]. The trip to computer station takes some minutes.

If forklift has RF terminal, when new task list is placed on the screen (no need to drive to computer station). In such case the RF terminal of forklift can have real-time communication with WMS. Also these portable computers can be used to map out the most efficient route. Using such possibilities, for example, during a tour the driver of forklift can be also instructed, to take items which have been just received at warehouse [10]. The driver of forklift can use portable scanner (it is used to improve the accuracy of information and data transmission speed and encourage information sharing).

In addition, forklift can be used to control stock level in storage locations. Stock levels are not taken into account in the model. There is only the possibility to identify, how stock accuracy affects the travel distance of forklift. In general, the goal for accuracy is 1 error per 1000 locations, but during process more errors appear. For higher stock accuracy level, scanning can help to find out mistakes. This is important seeking to avoid unnecessary travel distance. 


\subsection{Experiments}

For basic scenario 1000 replenishment tasks are entered to Excel simulation model and different tests are used. In addition, the total travel distance is splitted into two parts:

- The first distance when forks are empty is calculated. Such distance is calculated when forklift moves from computer station (depot) and comes back to computer station;

- The second distance when forks are not empty is calculated. Such distance is calculated when forklift moves with the pallet to new location.

By running simulation tests it is seen that the best travel distance is when RF is implemented and driving without computer station is used. In such case, the total travel distance decreases by 27-37\%.

The experiments demonstrate that RF-based process is giving the best results - the distance when forks are empty is the lowest comparing with the distance when paper is used in the process.

The distance when forks are empty is equal to $66 \%$ of total travel distance and is $20 \%$ lower comparing with the same distance when paper-based process is in place.

Fleisch and Tellkamp also suggest to study the relationship between inventory inaccuracy and actual performance in warehouse (i.e. the out-of-stock level, and its relation with travel distance) [19].

The goal for stock accuracy is 1 error per 1000 locations $(0.10 \%)$, but during process more errors appears. In the study inaccuracy means that if forklift during replenishment and pallet pick operations is directed to empty storage locations when unnecessary travel distance occurs. The correlation between inaccurate stock in storage locations and unnecessary travel distance is presented in Fig. 4.

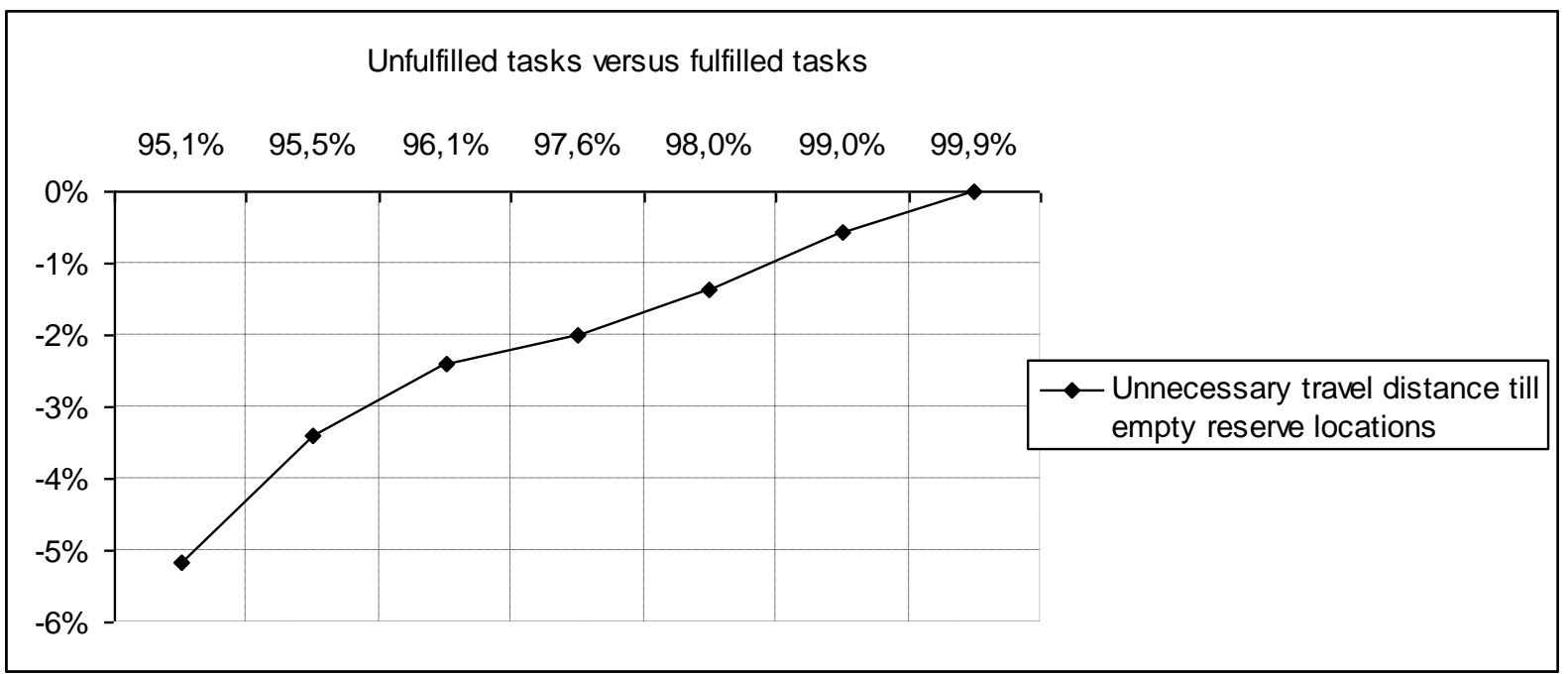

Figure 4: The correlation between inaccurate stock in reserve storage locations and the unnecessary travel distance of forklift (horizontal axe $-\%$ of reserve locations, vertical axe $-\%$ of travel distance).

The final results show that the travel distance of forklift has been reduced by $5.2 \%$ when $4.9 \%$ of out-of-stocks (49 out-of stock cases per 1000 tasks) is improved (Fig. 4).

The next research is dedicated to multiple-tasks approach. This approach is based on idea that the combination of different tasks can help to increase productivity. So, research provided herein also defines how to increase productivity by implementing multiple-tasks approach in WMS. In order to create multiple-tasks, the author find out that between 1000 tasks 393 tasks 
are put-away tasks, 319 - replenishment tasks, 38 - pallet pick tasks, 250 of them are "put to door" tasks. It is found that in order to perform put-away operations forklift has to return from the aisle to receiving area with empty forks. The same with pallet pick operations. So, the author combines these tasks (as in reference warehouse common doors are used for shipping and receiving). In addition, replenishment tasks (bypass tasks) are incorporated with the aim to cut travel distance between different aisles. Finally, 38 multiple-tasks are created. Each multiple-task consists of put-away, replenishment and pallet pick tasks (in the mentioned sequence).

Research results show that the travel distance of forklift is reduced by $9 \%$ when multipletasks approach is used in WMS. $9 \%$ reduction in total travel distance is received comparing with distance when multiple-tasks approach is not applied. In addition to this, investigations show that total travel distance can be reduced, when the total number of pallet picks is higher (in the reference warehouse the number of pallet pick tasks is low $-9-12 \%$ of all tasks are pallet pick tasks).

\section{CONCLUSIONS}

The research results show that the implementation of RF in warehouses is a priority. RFbased process gives the best results - the travel distance is the lowest comparing with travel distance when paper is used in the process. The experiments demonstrate that in the reference warehouse the travel distance of forklifts can be improved up to 27-37 \% when RF-based process is implemented comparing with travel distance when paper is used in the process.

The concluding remarks for the travel distance of RF-guided forklifts are as follows:

- the research results also show that stock accuracy is a priority seeking to reduce unnecessary travel distance;

- the experiments demonstrate that the higher number of multiple-tasks leads to significant reduction of total travel distance.

In the reference warehouse, the total travel distance and its parts are calculated through simulation; it is found that the travel distance when forks are empty is equal to $66 \%$ of total travel distance.

The presented results show that the travel distance of forklift can be also reduced by $9 \%$ when multiple-tasks approach is used in WMS.

The described experiment demonstrates that in considered situation the productivity of the processes (in which the forklifts with RF terminals are used) can be improved by $36-46 \%$ when RF-based process is implemented and multiple-tasks approach is used.

For optimizing the travelling of forklifts in warehouse new simulation model is created. Undertaken experiments have shown that new simulation model, can be applied for analyzing different scenarios.

\section{ACKNOWLEDGEMENT}

This paper was prepared under research for the COST-TERRA project (www.cost-terra.org), 2010.

\section{REFERENCES}

[1] Chan, F. T. S. (2002). Design of material handling equipment selection system: an integration of expert system with analytic hierarchy process approach, Integrated Manufacturing Systems, Vol. 13, No. 1, 58-68, doi:10.1108/09576060210411512 
[2] Cormier, G. (2005). Operational research methods for efficient warehousing, Langevin, A.; Riopel, D. (Eds.), Logistics systems: design and optimization, Springer Verlag, 93-122

[3] Shakantu, W.; Tookey, J. E.; Bowen, P. A. (2003). The hidden cost of transportation of construction materials: an overview, Journal of Engineering, Design and Technology, Vol. 1, No. 1, 103-118, doi:10.1108/eb060892

[4] Saenz, N. (2006). Order picking operations design, Forger, R. (Ed.), Perspectives on material handling practice, North Carolina, Charlotte, Material Handling Institute, 1-14

[5] Varila, M.; Seppanen, M.; Suomala, P. (2007). Detailed cost modelling: a case study in warehouse logistics, International Journal of Physical Distribution \& Logistics Management, Vol. 37, No. 3, 184-200, doi:10.1108/09600030710742416

[6] Bartholdi, J. J.; Hackman, S. T. (2006). Warehouse \& distribution science, The Logistics Institute, Georgia Institute of Technology

[7] De Koster, R.; Le-Duc, T.; Roodbergen, K. J. (2006). Design and control of warehouse order picking: a literature review, ERIM Report Series Research in Management, RSM Erasmus University, the Netherlands, 2-33

[8] Gross Asociates. Radio frequency applications in material handling: Receiving, Put away, Replenishing, Picking, Shipping, from http://www.grossassociates.com, accessed on 14-11-2010

[9] Hassan, M. M. D. (2010). A framework for selection of material handling equipment in manufacturing and logistics facilities, Journal of Manufacturing Technology Management, Vol. 21, No. 2, 246-268, doi:10.1108/17410381011014396

[10] Gong, Y. (2009). Stochastic modelling and analysis of warehouse operations, PhD Thesis, Erasmus University Rotterdam, The Netherlands, 58-69

[11] Kia, M.; Shayan, E.; Ghotb, F. (2000). The importance of information technology in port terminal operations, International Journal of Physical Distribution \& Logistics Management, Vol. 30, No. 3/4, 331-344, doi:10.1108/09600030010326118

[12] Caputo, A. C.; Pelagagge, P. M. (2008). Capacity upgrade criteria of large-intensive material handling and storage systems: a case study, Journal of Manufacturing Technology Management, Vol. 19 No. 8, 953-978, doi:10.1108/17410380810911727

[13] Chitale, A. K.; Gupta, R. C. (2007). Materials Management, PHI Learning Ltd

[14] Connolly, C. (2008). Warehouse management technologies, Sensor Review, Vol. 28, No. 2, 108114, doi:10.1108/02602280810856660

[15] Ackerman, K. B. (2001). Task interleaving - a significant step in improving warehouse productivity, Warehousing forum, Vol. 16, No. 3, 1-2

[16] Banker, S. (2009). Task Interleaving: An Advanced Warehouse Productivity Practice, from http://www.logisticsviewpoints.com, accessed on 01-07-2011

[17] Djassemi, M. (2007). Improving factory layout under a mixed floor and overhead material handling condition, Journal of Manufacturing Technology Management, Vol. 18, No. 3, 281-291, doi:10.1108/17410380710730611

[18] Petersen, C. G.; Schmenner, R. W. (1999). An evaluation of routing and volume - based storage policies in an order picking operations, American Institute for Decision Sciences, Vol. 30, No. 2, 2-7

[19] Fleisch, E.; Tellkamp, C. (2005). Inventory inaccuracy and supply chain performance: a simulation study of a retail supply chain, International Journal of Production Economics, Vol. 95, 373-385, doi:10.1016/j.ijpe.2004.02.003 